\title{
Correction to: First report of Aspergillus terreus causing sunken leaf spot on Dracaena aletriformis in India
}

\author{
Ashish Kumar Nayak ${ }^{1}$ - Samarendra Narayan Mallick ${ }^{2}$
}

Published online: 29 October 2020

(C) Australasian Plant Pathology Society Inc. 2020

\section{Correction to: Australasian Plant Pathology https://doi.org/10.1007/s13313-019-00653-Z}

Dr. Bandamaravuri Kishore Babu name was included in error and he is not associated with this manuscript.

The name of Dr. Mallick was incorrectly reported, the name should be corrected as follows: Samarendra Narayan Mallick. Also, Ashish Kumar Nayak is the new corresponding author of this article.

The original article has been corrected.

The online version of the original article can be found at https://doi.org/ 10.1007/s13313-019-00653-Z

Ashish Kumar Nayak

ashishrpre@gmail.com

1 Microbial Genomics and Diagnostic Lab, Regional Plant Resource Centre (RPRC), Bhubaneswar, Odisha 751015, India

2 Taxonomy and Conservation Division, Regional Plant Resource Centre, Nayapalli, Bhubaneswar, Odisha 751015, India 